\title{
Genetic divergence studies in clusterbean [Cyamopsis Tetragoloba (L.) Taub.] gen- otypes for seed yield and gum content under rain-fed conditions
}

\author{
Sukhdeep Singh*, Baldeep Singh and Gajraj Singh \\ Department of Genetics and Plant Breeding, CCS Haryana Agricultural University, Hisar-125004 (Haryana), INDIA \\ ${ }^{*}$ Corresponding author. E-mail: sukhdeep.sivia01@gmail.com
}

Received: April 29, 2016; Revised received: December 12, 2016; Accepted: February 6, 2017

\begin{abstract}
The genetic diversity among 33 cluster bean genotypes was evaluated under rain fed conditions during kharif 2012. The genetic material exhibited wide range of genetic diversity for all the twelve characters investigated. All the genotypes were grouped into seven different clusters. Cluster I was the largest comprising 11 genotypes followed by cluster II consisting of 8 genotypes, cluster V (5), cluster VI (4), cluster IV (2), cluster VII (2), cluster III (1). The clustering pattern indicated that there was lot of diversity among the genotypes and there was no relationship between the genetic and geographical diversity of the genotypes, but the distribution of the genotypes was random and independent. The intra cluster distance was highest at cluster VI followed by cluster I and II over others. The higher magnitude of inter-cluster distance were observed between cluster IV and VI (7.644) followed by cluster IV and V (7.582); cluster II and IV (6.802); cluster IV and VII (6.682); cluster I and IV (6.569); cluster II and VII (6.052); cluster III and IV (5.861) and cluster II and V (5.834) indicating wider genetic diversity between the genotypes in these clusters. The uses of genotypes in hybridization from these clusters having most of the desirable characters are likely to produce more transgressive segregants. It is suggested that genotypes belonging to the clusters I, IV and VII having diversified growth habit may be crossed with genotypes belonging to cluster II as they may be expected to produce good segregants with high yield potential.
\end{abstract}

Keywords: Cross combination, Cyamopsis tetragonoloba, Genetic diversity, Inter-cluster distance, Tocher's method

\section{INTRODUCTION}

Clusterbean [Cyamopsis tetragonoloba (L.) Taub.] popularly known as guar, is one of the most important kharif legumes and is well adapted to arid and semiarid regions of the world. The long deep taproot system enables the plant to grasp all the water in the soil making it an ultimate drought resistant crop. It is self-pollinated crop belongs to family Leguminosae and sub family paplionaceae having chromosome number $2 \mathrm{n}=14$. The seedpods grow in clusters giving guar the common name clusterbean. The origin of the crop has been suggested in India and Pakistan and tropical Africa (Vavilov, 1951). In India, this crop is mainly grown in Rajasthan, Gujarat, Haryana, Punjab and some parts of Uttar Pradesh and Madhya Pradesh and is an important component of cropping system in these regions. It is an annual plant, is grown for seed, green fodder, vegetable and green manuring. The endosperm of guar seed contains an important hydrocolloid named galactomannan. The galactomannan due to its specific qualities as thicker, binder and stabilizer has diversified industrial applications viz. paper, food, cosmetics, explosives, mining, petroleum, pharmaceuticals and well drilling etc. Recent rise in demand of guar in international market as a gum is attributed to its use in mining industry and petrochemical, where its use as viscous agent has been revolutionized the petrochemical industry and resulted in considerable increase in global natural gas production (Falasca et al., 2015). Because of industrial value, guar seed has great demand from foreign countries like USA, Germany, Britain, Italy, France, UAE, China, Japan, South Africa, Hong Kong and Australia etc. In world, guar is grown mostly in tropical deserts of Indian sub-continent. India share $80 \%$ of world production and only $20 \%$ is produced by all other countries like Pakistan, USA, Australia, South Africa, Sudan and Argentina. Thus, the total area of cluster bean in India is 4.25 million hectare and production is 2.41 million tones with productivity of $5.70 \mathrm{q} / \mathrm{ha}$. Rajasthan is one of the main producers of cluster bean contribute for 65 per cent of the total production of the India (Ministry of Agriculture Govt. of India, 2014). Average grain yield of clusterbean at national level is very low $(5.70 \mathrm{q} / \mathrm{ha})$. Therefore, development of new clusterbean varieties having high yield potential should be the main objective of the breeding program.

Genetic divergence is also of utmost importance for identifying appropriate genotypes as parents with their long-term potentialities. Mahalanobis $\mathrm{D}^{2}$ statistics is a powerful tool in quantifying the degree of divergence 
at the genotypic level with regard to characters that needed to be improved and provides to opportunity to identify putative parents for executing an effective breeding strategy. Until date, limited efforts have been made in characterizing clusterbean genotypes in India. Precise information about genetic divergence is critical for productive breeding programs, as genetically diverse parents are known to produce high heterotic effects consequently increasing yield in desirable segregants. $\mathrm{D}^{2}$ statistics, it has now become possible to quantify the degree of genetic divergence among the clusterbean genotypes. Therefore, the present investigation was aimed at ascertaining the nature and magnitude of genetic diversity among available genotypes for seed yield, its attributing traits and gum content to identify suitable parents for hybridization program.

\section{MATERIALS AND METHODS}

The experimental material for the present investigation comprising thirty-three genotypes of clusterbean maintained by Forage Section, Department of Genetics \& Plant Breeding, Chaudhary Charan Singh Haryana Agricultural University, Hisar. Total 33 cluster bean genotypes were collected from different major guar growing states for this study viz. Haryana, Rajasthan, Gujarat, Punjab and other north Indian states (Table 1). The experimental material was grown in a Randomized Block Design (RBD) with three replications during kharif 2012. Each genotype was planted in two rows of $4 \mathrm{~m}$ length with row-to-row distance of $45 \mathrm{~cm}$. The sowing was done with single row hand drill and after germination, plant to plant distance of $15 \mathrm{~cm}$ was maintained by manual thinning. All the recommended cultural practices were followed throughout the crop seasons to raise a good crop. Observations were recorded on five competitive plants excluding border plants in each genotype. Data on individual plants were recorded for days to $50 \%$ flowering, plant height $(\mathrm{cm})$, branches per plant, number of clusters per plant, number of pods per cluster, number of pods per plant, number of seeds per pod, pod length $(\mathrm{cm})$, days to maturity, 100-seed weight (g), seed yield per plant $(\mathrm{g})$ and gum content (\%). Gum content in the seed was estimated by the method of Das et al. (1977) and modified by Joshi (2004). The analysis of variance for Randomized Block Design was carried out for individual characters to test the significance of difference among the genotypes following the method as suggested by Panse and Sukhatme (1967). Mahalanobis $\mathrm{D}^{2}$ statistic as suggested by (Rao, 1952) was used to measure genetic divergence. Group constellation was performed according to the method suggested by Tocher.

Contribution of individual traits toward genetic divergence was quantified on the basis of coefficient of variation at both genotypic and inter-cluster level (Vavilov, 1951).

\section{RESULTS AND DISCUSSION}

Genetic diversity is the basic requirement for successful breeding programme. Collection and evaluation of germplasm line and genotypes of any crop is a pre-requisite for any programme and provides a greater scope for exploiting genetic diversity. The multivariate analysis $\left(\mathrm{D}^{2}\right)$ is a powerful tool to measure the genetic divergence within a set of genotypes. Mean squares due to genotypes were highly significant for all the characters except for 100 seed weight and number of pods per cluster indicating existence of significant genetic variability among the genotypes used in the present study. The coefficient of variation was low for all the traits, which indicates that the local control of experiment was effectively done (Table 2).

The estimates of $\mathrm{D}^{2}$ values revealed wide range of diversity among the genotypes. This was further substantiated by the grouping pattern of the genotypes (Table 3). The 33-germplasm lines under study were grouped into seven clusters with the cluster I having the maximum 11 genotypes followed by cluster II (8), cluster V (5), cluster VI (4), cluster IV (2), cluster VII

Table 1. Source of clusterbean genotypes.

\begin{tabular}{lcl}
\hline \multicolumn{1}{c}{ Source } & $\begin{array}{c}\text { Number of } \\
\text { genotypes }\end{array}$ & \multicolumn{1}{c}{ Name of genotypes } \\
\hline RAU, Durgapura, Rajasthan & 11 & RGC 936, RGC 471, RGC 986, RGC 1033, RGC 1055, RGC \\
& & $\begin{array}{l}\text { 197, RGC 1066, RGC1003, RGC 1017, RGC1038, RGC 1002 } \\
\text { HG 2-20, HG 3-52, HG 870, HG 2-4, HG 884, HG 563, HG 75, } \\
\text { HG 258, HG 365, HG 182, HG 100, HG 832, HVG 2-30, HFG } \\
\end{array}$ \\
& 14 & 119 \\
GAU, Gujarat & 3 & GAUG 0013, GAUG 0001, GG 1 \\
Miscellaneous & 3 & FS 277, ML 119, VIKAS 35 \\
CAZRI, Jodhpur, Rajasthan & 1 & CAZG 97-1 \\
PAU, Ludhiana & 1 & PNB \\
\hline
\end{tabular}


Sukhdeep Singh et al. / J. Appl. \& Nat. Sci. 9 (1): 389 - 394 (2017)

Table 2. Analysis of variance for seed yield and its component characters in clusterbean.

\begin{tabular}{lccccc}
\hline $\begin{array}{l}\text { Source of variation/ } \\
\text { Characters }\end{array}$ & $\begin{array}{c}\text { Replications } \\
\mathbf{d f}=\mathbf{2}\end{array}$ & $\begin{array}{c}\text { Treatments } \\
\mathbf{d f}=\mathbf{3 2}\end{array}$ & $\begin{array}{c}\text { Error } \\
\mathbf{d f}=\mathbf{6 4}\end{array}$ & C.D. (5\%) & $\begin{array}{c}\text { Coefficient of } \\
\text { variation (CV) }\end{array}$ \\
\hline Seed Yield /Plant (g) & 1.02 & $21.44^{* *}$ & 1.00 & 1.63 & 12.60 \\
Days to 50\% Flowering & 0.52 & $103.44^{* *}$ & 0.31 & 0.90 & 1.16 \\
Plant Height (cm) & 17.81 & $3,224.69^{* *}$ & 26.38 & 8.38 & 4.18 \\
100 Seed Weight (g) & 0.07 & $0.19^{* *}$ & 0.02 & 0.24 & 4.48 \\
No. of Clusters/Plant & 16.76 & $31.26^{* *}$ & 1.30 & 1.86 & 9.74 \\
No. of Pods/Cluster & 1.04 & $0.61^{* *}$ & 0.37 & 1.00 & 16.05 \\
No. of Pods/Plant & 24.86 & $235.41^{* *}$ & 12.92 & 5.86 & 9.97 \\
No. of Seeds/Pod & 1.98 & $1.07^{* *}$ & 0.27 & 0.85 & 6.00 \\
Pod Length (cm) & 0.07 & $2.43^{* *}$ & 0.26 & 0.83 & 8.90 \\
Gum Content (\%) & 7.54 & $19.82^{* *}$ & 3.99 & 3.26 & 7.99 \\
Days to Maturity & 4.37 & $535.31^{* *}$ & 1.73 & 2.14 & 1.26 \\
No. of Branches/Plant & 0.39 & $21.67^{* *}$ & 0.50 & 1.15 & 13.01 \\
\hline
\end{tabular}

** Significant at $1 \%$ level of probability

Table 3. Clustering pattern of 33 genotypes of clusterbean.

\begin{tabular}{ccl}
\hline Cluster & $\begin{array}{c}\text { No. of } \\
\text { genotypes }\end{array}$ & \multicolumn{1}{c}{ Genotype } \\
\hline 1 Cluster & 11 & $\begin{array}{l}\text { HG 2-20, VIKAS 35, RGC 1017, RGC1038, RGC1002, ML 119, RGC } \\
\text { 1003, GAUG 0001, CA2G 97-1, RGC 936, RGC 1055 }\end{array}$ \\
2 Cluster & 8 & HG 870, GAUG 0013, HG 884, HG 365, HG 2-4, RGC 1033, HG 563, HG \\
3 Cluster & 1 & RGC 1066 \\
4 Cluster & 2 & PNB, HVG 2-30 \\
5 Cluster & 5 & HG 75, GG 1, HG 258, HG 182, HFG 119 \\
6 Cluster & 4 & HG 832, RGC 471, RGC 986, HG 3-52 \\
7 Cluster & 2 & FS 277, RGC 197 \\
\hline
\end{tabular}

Table 4. Average intra (in bold) and inter-cluster distances among 33 genotypes of clusterbean .

\begin{tabular}{lccccccc}
\hline & 1 Cluster & 2 Cluster & 3 Cluster & 4 Cluster & 5 Cluster & 6 Cluster & 7 Cluster \\
\hline 1 Cluster & $\mathbf{2 . 8 4 2}$ & 3.233 & 4.066 & 6.569 & 5.495 & 5.387 & 5.793 \\
2 Cluster & & $\mathbf{2 . 7 2 1}$ & 4.015 & 6.802 & 5.834 & 5.674 & 6.052 \\
3 Cluster & & $\mathbf{0 *}$ & 5.861 & 5.282 & 5.686 & 5.232 \\
4 Cluster & & & $\mathbf{2 . 1 2 5}$ & 7.582 & 7.644 & 6.682 \\
5 Cluster & & & & $\mathbf{2 . 3 3 2}$ & 3.331 & 5.458 \\
6 Cluster & & & & & $\mathbf{3 . 2 5 3}$ & 4.845 \\
7 Cluster & & & & & & $\mathbf{1 . 9 5 5}$ \\
\hline
\end{tabular}

* Contain single branched genotype 
Sukhdeep Singh et al. / J. Appl. \& Nat. Sci. 9 (1): 389 - 394 (2017)

Table 5. Pre cent contribution of different characters to total divergence in clusterbean genotypes.

\begin{tabular}{lcc}
\hline Characters & No. of First Rank & \% Contribution \\
\hline Seed Yield /Plant (g) & 86.80 & 10.42 \\
Days to 50\% Flowering & 39.05 & 4.69 \\
Plant Height (cm) & 115.10 & 13.82 \\
100 Seed Weight (g) & 27.20 & 3.27 \\
No. of Clusters/Plant & 87.10 & 10.46 \\
No. of Pods/Cluster & 39.50 & 4.74 \\
No. of Pods/Plant & 70.10 & 8.41 \\
No. of Seeds/Pod & 32.00 & 3.84 \\
Pod Length (cm) & 83.50 & 10.03 \\
Gum Content (\%) & 21.35 & 2.56 \\
Days to Maturity & 39.50 & 4.74 \\
No. of Branches/Plant & 191.80 & 23.02 \\
\hline Total & $\mathbf{8 3 3 . 0 0}$ & $\mathbf{1 0 0 . 0 0}$ \\
\hline
\end{tabular}

(2) and cluster III (1). This envisaged that the genotypes grouped within a particular cluster are more or less genetically similar to each other and apparent wide diversity is mainly due to the remaining genotypes distributed over rest of the other clusters. Grouping of genotypes by multivariate method in the present study is the practical value of the breeders. Representative genotypes may be chosen from particular cluster for genetic base enhancement. In this clustering pattern cluster IV has two genotypes viz., PNB and HVG 2-30, these genotypes mostly used as vegetative purpose. The cluster III has a single genotype viz., RGC 1066, this genotype have unique feature high yielding with non-branching habit on the hand mostly high yielding genotypes grouped in cluster II and high gum content genotypes grouped in cluster I. Clustering pattern of genotypes in this study revealed that genotypes from different geographic regions are grouped together in a cluster and vice-versa suggesting that the geographical diversity does not necessarily represent genetic diversity. Our results are in accordance with the findings of Singh et al., (2003), Henry and Mathur (2007), Pathak et al., (2009), Girish et al., (2012), Sultan et al., (2012) and Manivannan et al., (2015) who concluded that there is no or less correlation between geographic location and genetic diversity in clusterbean.

Average intra- and inter-cluster distances ( $\mathrm{D}^{2}$ values) among 7 clusters are given in Table 4 . The intra-cluster $\mathrm{D}^{2}$ values varied from 0 to 3.253 within cluster and 3.233 to 7.644 between clusters. This indicated that cluster were homogenous within themselves and heterogeneous between themselves. The value of intra-cluster distance for cluster III was zero as it has only one genotype in the cluster. Cluster VII had lowest intra-cluster distance of 1.955 and cluster VI accounted for highest intra-cluster distance of 3.253. Maximum inter cluster distance was observed between cluster IV and VI (7.644) followed by cluster IV and V (7.582); cluster II and IV (6.802); cluster IV and VII (6.682); cluster I and IV (6.569); cluster II and VII (6.052) and cluster III and IV (5.861) indicating wider genetic diversity between the genotypes in these clusters. Selection of diverse parent having most of the desirable characters from such clusters in breeding programs is likely to produce more transgressive segregants and heterotic $\mathrm{F}_{1}$ 's when crossed. The cluster means reflected appreciable variation for almost all the characters among different clusters. Similar results were obtained by Manivannan et al., (2013) and Kumar et al., (2014). Study of Manivannan et al. (2013) found wide range of genetic diversity for twelve characters investigated and grouped into 15 different clusters. The maximum intra cluster distance was observed in cluster XIV indicated that genotypes are having diverse genetic architecture and maximum inter-cluster distance recorded between cluster VI and cluster XV, indicating the presence of wide range of variability among the genotypes of the cluster. One another study conducted by Kumar et al. (2014) exhibited wide ranges of genetic diversity for all the characters. Based on $\mathrm{D}^{2}$ values, 30 genotypes were 
Sukhdeep Singh et al. / J. Appl. \& Nat. Sci. 9 (1): 389 - 394 (2017)

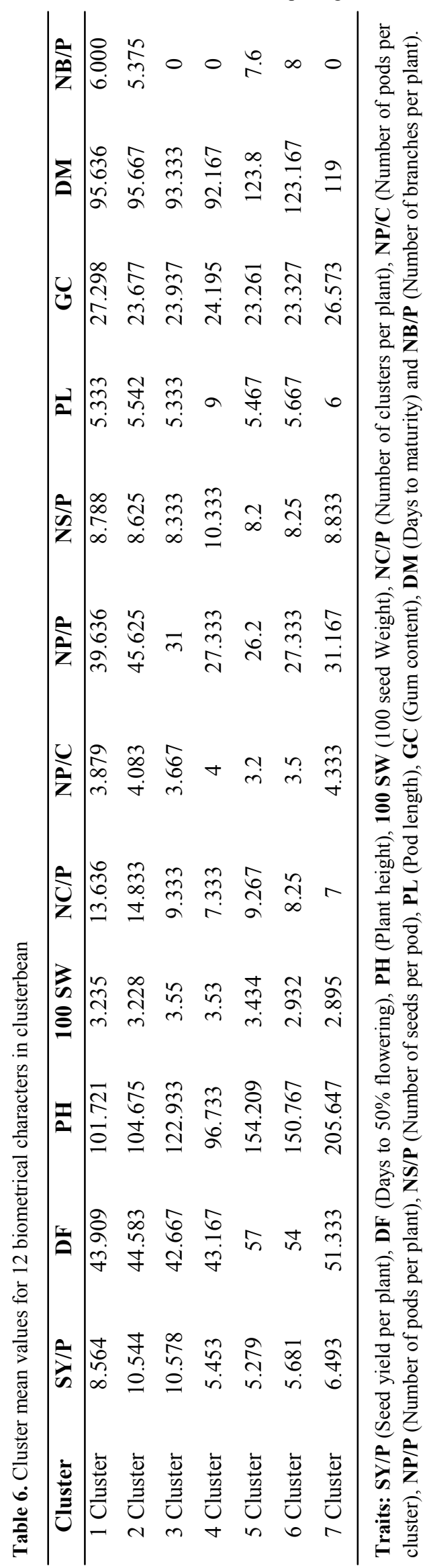

classified into five clusters. Maximum inter- cluster distance was between cluster I and cluster II and intra-cluster distance in cluster III, indicating the presence of genetic diversity among the genotypes between the cluster bean. These both finding are relevance to the present study based on diverse genotypes grouped in different cluster and the distance between these cluster have maximum.

The characters like number of branches per plant (23.02), plant height (13.82), number of clusters per plant (10.46), seed yield per plant (10.42), pod length (10.03) and number of pods per plant (8.41) contributed more than $75 \%$ of the total divergence in the clusterbean genotypes examined (Table 5). The lowest contribution (less than 4) in genetic diversity was observed from various traits as gum content (2.56) followed by 100 seed weight (3.27) and number of seeds per pod (3.84). The cluster mean estimated over the genotypes included in a cluster revealed considerable variation among the groups for 12 characters are presented vide Table 6 . Cluster $\mathrm{V}$ possessed highest mean values for days to flowering (57) and days to maturity (123.8), Cluster VII had highest mean value for plant height (205.65) and number of pods per cluster (4.33), Cluster III for 100 seed weight (3.55) and seed yield per plant (10.58), Cluster II had highest mean value for number of clusters per plant (14.83) and number of pods per plant (45.62), Cluster IV had highest mean value for number of seeds per pod (10.33) and pod length (9), Cluster I had highest mean value for gum content (27.30) and Cluster VI for number of branches per plant (8). Maximum amount of heterosis is generally expected in cross combinations involving the presents belonging to most divergent clusters. Our results are accordance with the finding of Singh et al. (2003), Pathak et al. (2009) and Chaudhary et al. (2010), Rai et al. (2013) and Manivannan et al. (2015). The results of these studies revealed that the selection of genotypes for hybridization program based on their inter-culture distance and highest mean value. In present investigation, the selection of parents for hybridization program is based on the same principle such as inter-cluster distance and highest mean value of yield, gum and its contributing characters.

\section{Conclusion}

Based on the results of present investigation, an extensive range of genetic diversity has been explored in clusterbean genotypes. On this basis of inter-cluster distances and pre se performances observed of important agro-morphological traits like greater yield potential, gum content, pods per plant and early maturity, etc. served as criterion to select promising clusterbean genotypes viz., HG 2-20, ML 119, HG 563, HG 100, HG 884, CAZG 97-1, PNB, HVG 2-30, RGC 1017, RGC 1003 which will be suited to northern 
Table 7. Suggested hybridization programme.

\begin{tabular}{cl}
\hline Cluster pair & Crosses suggested \\
\hline 1 & HG 100 (cluster II) x ML 119 (cluster I) \\
& HG 100 (cluster II) x CAZG 97-1 (cluster I) \\
& HG 563 (cluster II) x PNB (cluster IV) \\
& HG 563 (cluster II) x HVG 2-30 (cluster IV) \\
2 & RGC 1017 (cluster I) x HVG 2-30 (cluster IV) \\
& RGC 1017 (cluster I) x HG 100 (cluster II) \\
& HG 2-20 (cluster I) x HG 884 (cluster II ) \\
5 & PNB (cluster IV) x HG 100 (cluster II) \\
5 & RGC 1003 (cluster I)x CAZG 97-1 (cluster IV)
\end{tabular}

part of India. Hybridization between these genotypes will be generate more variability which can facilitate selection of elite plants for seed yield and gum content in segregating generations (Table 7). Such a proposition would enable plant breeders to accelerate the pace of progress in varietal development in clusterbean for a competitive world market.

\section{REFERENCES}

Anonymous (2014). Agricultural-Statistics-At-Glance. Retrieved from eands.dacnet.nic.in

Chaudhary, O.P., Sastry, E.V.D., Singh, N.P. and Chaudhary, S.P.S. (2010). Genetic divegence analysis in clusterbean [Cyamopsis tetragonoloba (L.) Taub.]. Journal of Arid Legumes, 7 (1): 65-69

Das, B., Arora, S.K. and Luthra, Y.P. (1977). A rapid method of determination of gum in guar [Cyamopsis tetragonoloba (L.) Taub.]. In : Proc. First ICAR Guar Res. Workshop. CAZRI, Jodhpur. pp. 117-123

Falasca, S.L., Miranda, C., and Pitta-Alvarez, S. (2015). Modeling an agroclimatic zoning methodology to determine the potential growing areas of Cyamopsis tetragonoloba (cluster bean) in Argentina. Advance Applied and Agriculture Sciences, 3: 23-39

Girish, M.H., Gasti, V.D., Thammaiah, N., Kerutagi, M.G., Mulge, R., Shantappa, T. and Mastiholi, A.B. (2012). Genetic divergence studies in clusterbean genotypes [Cyamopsis tetragonoloba (L.) Taub.]. Karnataka Journal Agriculture Science, 25 (2): 245-247

Henry, A. and Mathur, B.K. (2007). Genetic diversity in clusterbean germplasm. Journal of Arid Legumes, 4 (2): $134-136$

Joshi, U.N. (2004). Advances in chemistry, Biochemistry and industrial utilization of guar seed. In : "Guar" (J.V.Singh and B.S.Dahiya eds.), Indian Society of Forage Research, Hisar and Agricultural and Processed Food Products export development authority (APEDA), New Dehli, India, pp : 197-227

Kumar Vikas, Ram R.B. and Yadav Ram Kumar (2014). Genetic diversity in clusterbean [Cyamopsis tetragonol- oba (L.) Taub.] for morphological characters. Indian Journal of Science and Technology, 7(8), 1144-1148

Mahalanobis, P.C. (1936). On the generalized distance in statistic. Proceedings of National Institute of Sciences, India, 2: 49-55

Manivannan, A. and Anandakumar, C.R. (2013). Genetic divergence studies in clusterbean [Cyamopsis tetragonoloba (L.) Taub.] genotypes. Indian Journal of Science and Technology, 6(10): 5337-5341

Manivannan, A., Anandakumar, C.R., Ushakumari, R. and Dahiya, G.S. (2015). Genetic diversity of guar genotypes [Cyamopsis tetragonoloba (L.) Taub.] based on agro-morphological traits. Bangladesh Journal of Botany, 44(1): 59-65

Panse, V.G. and Sukhatme, P.V. (1967). Statistical methods for agricultural workers II Ed. ICAR Publication, New Dehli.

Pathak Rakesh., Singh Manjit and Henry A. (2009). Genetic divergence in clusterbean [Cyamopsis tetragonoloba (L.) Taub.] for seed yield and gum content under rainfed condition. Indian Journal of Agriculture Sciences 79(7): 559-61

Rai, P.S. and Dharmatti, P.R. (2013). Genetic divergence studies in clusterbean genotypes [Cyamopsis tetragonoloba (L.) Taub.]. Global Journal of Science Frontier Research Agriculture and Veterinary, 13(5): 45-48.

Rao, C.R. (1952). Advanced statistical methods in biometric research. John Wiley and Sons Inc., New York.

Singh, N.P., Choudhary, A.K. and Choudhary, S.P.S. (2003). Genetic divergence in clusterbean (Cyamopsis tetragonoloba). Indian Journal of Agriculture Sciences, 73(6): 356-357

Sultan Maria, Ashiq Rabbani M., Shinwari Zabta K. and Masood M. Shahid (2012). Phenotypic divergence in Guar (Cyamopsis Tetragonoloba) Landrace genotypes of Pakistan. Pakistan Journal of Botany, 44: 203-210

Vavilov, N.I. (1951). The origin, variation, immunity and breeding of cultivated plants. Chronica Botanica 13. 